\title{
Effects of different doses of cisatracurium besilate on hemodynamics and postoperative cognitive function in patients undergoing radical resection of lung cancer
}

\author{
QINGXIANG CAO* ${ }^{*}$ XIAOPENG TIAN* ${ }^{*}$ CHUANZHEN DONG, HUIMIN BU and YI CHENG \\ Department of Anaesthesia, Dongying People's Hospital, Dongying, Shandong 257000, P.R. China
}

Received August 30, 2018; Accepted May 28, 2019

DOI: $10.3892 / \mathrm{ol} .2019 .10503$

\begin{abstract}
The effects of different doses of cisatracurium besilate on perioperative hemodynamics and early postoperative cognitive function in patients undergoing radical resection of lung cancer were investigated. One hundred and thirty-six patients who underwent radical resection of lung cancer from June 2013 to June 2016 in Dongying People's Hospital were retrospectively analyzed. Patients who were not given atracurium were selected as the control group $(n=35)$. According to the different anesthetic doses, patients in the experimental group were separated into low dose $(0.15 \mathrm{mg} / \mathrm{kg}$ cisatracurium besilate) group (LD group, $\mathrm{n}=34)$, medium dose $(0.2 \mathrm{mg} / \mathrm{kg}$ cisatracurium besilate) group (MD group, $n=36$ ) and high dose $(0.3 \mathrm{mg} / \mathrm{kg}$ cisatracurium besilate) group (HD group, $\mathrm{n}=31$ ). The mean arterial pressure and heart rate (HR) were recorded before induction of anesthesia (T0), at the time of entering pleural cavity (T1), at the end of surgery (T2), and 1 day after surgery (T3). The Mini-Mental State Examination (MMSE) was used to evaluate the postoperative cognitive function scores of the 4 groups 1 day before operation and on the 1st, 3rd and 7th day after surgery. The agitation of patients at 6 and $12 \mathrm{~h}$ after operation was evaluated by Ramsay sedation score. There was no significant difference in arterial pressure among the four groups at T2 and T3 ( $\mathrm{P}>0.05)$. There was no significant difference in terms of MMSE among the four groups 1 day before operation, 3 days after operation and 7 days after operation, but the MMSE score of the control group was significantly lower than that of the LD, MD and HD groups 1 day after surgery $(\mathrm{P}<0.05)$. Therefore, cisatracurium besilate can stabilize hemodynamics during radical operation of lung cancer and reduce the incidence of postoperative cognitive dysfunction, and it has no close association with the dose.
\end{abstract}

Correspondence to: Dr Yi Cheng, Department of Anaesthesia, Dongying People's Hospital, 317 Nanyi Road, Dongying, Shandong 257000, P.R. China

E-mail: c6e46r@163.com

*Contributed equally

Key words: cisatracurium besilate, dose, radical resection of lung cancer, cognitive function, sedation score

\section{Introduction}

Lung cancer is a malignant tumor originating from the bronchial mucosa, and its morbidity and mortality are the highest in cancer worldwide (1). In recent years, with the environmental pollution and lifestyle changes, the incidence of lung cancer is also rising (2). At present, for the treatment of lung cancer, operation is still the preferred method. Operation can remove the primary lesion and metastatic lesions, laying the foundation for subsequent treatments (3). After surgical resection, it can reduce the risk of metastasis, proliferation and invasion of cancer cells (4). However, surgical treatment causes great damage to the patients' body. Due to anesthesia and analgesia, many patients have severe agitation and cognitive impairment during anesthesia recovery, which results in impairment of the patient's cognition, consciousness and memory (5). A study (6) has shown that postoperative cognitive dysfunction is closely related to anesthesia and analgesia during surgery. Due to the development of minimally invasive techniques, laparoscopic radical surgery for lung cancer reduces the trauma and risk of lung cancer surgery, and can also promote the rapid recovery of patients. Currently, it is widely used in clinical practice $(7,8)$. At present, general anesthesia combined with epidural block is still the main choice for anesthesia in lung cancer radical surgery. Although it has improved postoperative agitation and cognitive dysfunction, the exploration of different anesthetic drugs is still the focus clinically (9).

Cisatracurium besilate is the most commonly used non-depolarizing muscle relaxant in general anesthesia combined with epidural anesthesia, and compared with other non-depolarizing drugs, it has the advantages of less cardiovascular effect and no accumulation in vivo following massive use $(10,11)$. A study (12) has shown that with the increase in dose of cisatracurium besilate, the onset time will be shortened, but there is no significant difference in other aspects such as heart rate (HR) and airway resistance.

In order to verify the above conclusions and to improve the postoperative cognitive impairment in patients undergoing radical resection of lung cancer, the effects of different doses of cisatracurium besilate on perioperative hemodynamics and the postoperative cognitive function recovery in adult radical resection of lung cancer were compared to provide a better plan for clinical general anesthesia. 
Table I. General information [n, (\%)].

\begin{tabular}{|c|c|c|c|c|c|c|}
\hline Indexes & $\begin{array}{l}\text { LD group } \\
(n=34)\end{array}$ & $\begin{array}{l}\text { MD group } \\
(\mathrm{n}=36)\end{array}$ & $\begin{array}{l}\text { HD group } \\
\quad(n=31)\end{array}$ & $\begin{array}{l}\text { Control group } \\
\quad(\mathrm{n}=35)\end{array}$ & $\chi^{2}$ value & P-value \\
\hline Sex & & & & & 0.025 & 0.999 \\
\hline Male & $18(52.94)$ & $19(52.78)$ & $16(51.61)$ & $18(51.43)$ & & \\
\hline Female & $16(47.06)$ & $17(47.22)$ & $15(48.39)$ & $17(48.57)$ & & \\
\hline Age (years) & & & & & 0.122 & 0.989 \\
\hline$\leq 45$ & $14(41.18)$ & 15 (41.67) & $12(38.71)$ & $15(42.86)$ & & \\
\hline$>45$ & $20(58.82)$ & $21(58.33)$ & $19(61.29)$ & $20(57.14)$ & & \\
\hline $\operatorname{BMI}\left(\mathrm{kg} / \mathrm{m}^{2}\right)$ & & & & & 0.022 & 0.999 \\
\hline$\leq 22$ & $15(44.12)$ & $16(44.44)$ & $14(45.16)$ & $16(45.71)$ & & \\
\hline$>22$ & $19(55.88)$ & $20(55.56)$ & $17(54.84)$ & $19(54.29)$ & & \\
\hline Pathological stage & & & & & 0.212 & 0.976 \\
\hline I-II & $19(55.88)$ & $21(58.33)$ & $19(61.29)$ & $20(57.14)$ & & \\
\hline III & $15(44.12)$ & $15(41.67)$ & $12(38.71)$ & $15(42.86)$ & & \\
\hline Educational level & & & & & 0.122 & 0.989 \\
\hline Junior high school and above & $21(61.76)$ & $23(63.89)$ & $20(64.52)$ & $23(65.71)$ & & \\
\hline Below junior high school & $13(38.24)$ & $13(36.11)$ & $11(35.48)$ & $12(34.29)$ & & \\
\hline Pathological type & & & & & 0.243 & 0.999 \\
\hline Squamous cell carcinoma & $12(35.29)$ & $13(36.11)$ & $10(32.26)$ & $12(34.29)$ & & \\
\hline Undifferentiated carcinoma & $11(32.35)$ & $11(30.56)$ & $11(35.48)$ & $12(34.29)$ & & \\
\hline Adenocarcinoma & $11(32.35)$ & $12(33.33)$ & $10(32.26)$ & $11(31.43)$ & & \\
\hline
\end{tabular}

$\chi^{2}$ test was used in this table.

\section{Patients and methods}

General information. One hundred and thirty-six patients who underwent radical resection of lung cancer from June 2013 to June 2016 in Dongying People's Hospital (Dongying, China) were retrospectively analyzed. The mean age was $45.5 \pm 5.2$ years. All patients underwent general anesthesia combined with epidural anesthesia. One hundred and one patients given cisatracurium besilate were selected as the experimental group. According to different doses, 34 patients were in the low dose group (LD group), 36 patients were in the medium dose group (MD group) and 31 patients were in the high dose group (HD group) and 35 patients who were not given atracurium were selected as the control group. There were no significant differences in sex, age and pathological classification among the four groups $(\mathrm{P}>0.05)$, as shown in Table I.

Inclusion and exclusion criteria. Inclusion criteria: Patients diagnosed with lung cancer by pathological diagnosis. Exclusion criteria: Patients who had undergone chemotherapy and radiotherapy before surgery; patients with coagulopathy; patients with sever liver and kidney dysfunction; patients who did not cooperate with the examination or had cognitive dysfunction; and patients with communication impairment.

This study was approved by the Ethics Committee of Dongying People's Hospital. All the patients or their guardians agreed to participate in the experiment and signed the informed consent.
Experimental drugs. Midazolam was purchased from Jiangsu Enhua Pharmaceutical Co.,Ltd.(SFDA approval no.H10980026); Sufentani was purchased from Yichang Humanwell Pharmaceutical Co., Ltd. (SFDA approval no. H20054256); cisatracurium besilate was purchased from Dongying (Jiangsu) Pharmaceutical Co., Ltd. (SFDA approval no. H20060927).

Experimental methods. All the patients were routinely fasted and water-deprived for $8 \mathrm{~h}$ before surgery. For the operation, the patient was in lateral position. The peripheral vein was opened and the electrocardiograph was performed. The patient's blood pressure, heart rate, pulse rate and blood oxygen saturation were detected. Anesthesia was performed with midazolam $0.02 \mathrm{mg} / \mathrm{kg}+$ sufentanil $0.6 \mu \mathrm{g} / \mathrm{kg}$, and then cisatracurium besilate was administered for muscle relaxation, $0.15 \mathrm{mg} / \mathrm{kg}$ in the LD group, $0.2 \mathrm{mg} / \mathrm{kg}$ in the MD group, $0.3 \mathrm{mg} / \mathrm{kg}$ in the HD group. Patients in the control group did not recieve atracurium, and all patients received $0.2 \mu \mathrm{g} / \mathrm{kg}$ midazolam for intraoperative maintenance of anesthesia. The dose of cisatracurium besilate was reported previously (13), as well as doses of other drugs (14).

Tracheal intubation and one-lung ventilation were performed. The 4th or 5th intercostal space of the axillary front was taken from the affected side for a $3-\mathrm{cm}$ incision. The rib was propped open with a protective sheath and the thoracoscopic probe was placed. Then the pulmonary lobes and associated arteries, veins and bronchus where the tumor was located were removed. The resected specimens were removed from the body into the specimen bag. The mediastinal lymph nodes of the 
Table II. Changes in arterial pressure at different time-points in the four groups of patients $(\mathrm{mmHg})$.

\begin{tabular}{|c|c|c|c|c|c|c|}
\hline Time & LD group $(n=34)$ & MD group $(n=36)$ & HD group $(n=31)$ & Control group $(n=35)$ & F value & P-value \\
\hline T0 & $95.4 \pm 5.1$ & $95.1 \pm 5.6$ & $95.7 \pm 5.2$ & $96.4 \pm 6.5^{b}$ & 0.343 & 0.794 \\
\hline $\mathrm{T} 1$ & $93.1 \pm 5.2^{\mathrm{a}}$ & $93.3 \pm 5.2^{\mathrm{a}}$ & $92.9 \pm 5.4^{\mathrm{a}}$ & $104.4 \pm 5.2$ & 36.21 & $<0.001$ \\
\hline $\mathrm{T} 2$ & $94.5 \pm 5.2$ & $94.8 \pm 5.5$ & $94.1 \pm 5.2$ & $96.9 \pm 4.7^{\mathrm{b}}$ & 2.002 & 0.117 \\
\hline $\mathrm{T} 3$ & $94.7 \pm 5.3$ & $96.4 \pm 4.9$ & $95.4 \pm 5.1$ & $97.6 \pm 5.0^{\mathrm{b}}$ & 2.117 & 0.101 \\
\hline $\mathrm{F}$ value & 1.168 & 2.071 & 1.879 & 16.77 & - & - \\
\hline P-value & 0.325 & 0.107 & 0.137 & $<0.001$ & - & - \\
\hline
\end{tabular}

${ }^{a} \mathrm{P}<0.05$, compared with the control group within the same group. ${ }^{\mathrm{b}} \mathrm{P}<0.05$, compared with $\mathrm{T} 1$ within the same group. Repeated measures ANOVA was used for comparison at different time-points, and one-way ANOVA was used for comparison between the groups. The Bonferroni test was the post hoc test.

patient were dissected, and the lymph nodes in the 4,7,9,10 and 11 regions on the right side, and in the 5, 7, 9, 10 and 11 regions on the left side were dissected. The drainage tube was placed to perform negative pressure drainage. After the operation, the patients were sent back to the ward after resuming spontaneous breathing and physical signs being stable.

Observation indicators. The mean arterial pressure and HR of patients before anesthesia induction (T0), when entering the pleural cavity (T1), after surgery (T2), and 1 day after surgery (T3) were recorded. The postoperative cognitive function scores of the 4 groups were scored by the Mini-Mental State Examination (MMSE) (15) on the 1st day before surgery and on the 1st, 3rd, and 7 th postoperative day. The sedation scores of patients at 6 and $12 \mathrm{~h}$ after surgery were evaluated by Ramsay sedation score (16). MMSE content includes orientation, language, memory, attention, calculation, reading, spatial structure, a total of 30 points, the boundary between normal and abnormal is related to the level of education: illiteracy $<17$ points; primary school $<20$ points; middle school or above $<24$ points was considered to have cognitive disorders, and a cognitive impairment was considered when the score was 2 points lower than the preoperative baseline value. Ramsay calming scoring criteria: 1: anxious; 2: quiet cooperation; 3: lethargy, but responsive to commands; 4: asleep, but can be awakened; 5: slow respiratory response; 6: deep sleep.

Statistical analysis. Statistical analysis was performed using SPSS 17.0 (Asia Analytics Formerly SPSS China) statistical software. Measurement data were expressed as mean \pm standard deviation. Multiple time-points were compared using repeated measures analysis of variance. Comparison of two time-points was performed by paired t-test. One-way analysis of variance was used for comparison among multiple groups and comparison between $6 \mathrm{~h}$ after and $12 \mathrm{~h}$ after surgery, and the Bonferroni test was the post hoc test. The enumeration data expressed as n (\%) were analyzed by Chi-square test, and Pearson analysis was used for correlation analysis. $\mathrm{P}<0.05$ was considered to indicate a statistically significant difference.

\section{Results}

Changes in the indicators of patients in the four groups at different time-points. At T0, there was no significant difference in mean arterial pressure and HR among the four groups $(\mathrm{P}>0.05)$. At $\mathrm{T} 1$, the mean arterial pressures of $\mathrm{LD}$, $\mathrm{MD}$ and HD groups were significantly lower than that of the control group $(\mathrm{P}<0.05)$. There was no significant difference in mean arterial pressure among the four groups at $\mathrm{T} 2$ and T3 ( $\mathrm{P}>0.05)$. There was no significant difference in the mean arterial pressure among the $\mathrm{LD}, \mathrm{MD}$ and $\mathrm{HD}$ groups at T0-T3 $(\mathrm{P}>0.05)$. The mean arterial pressure at $\mathrm{T} 1$ of the control group was higher than that at T0, T2 and T3 $(\mathrm{P}<0.05)$, and there was no significant difference in the mean arterial pressure in the control group at T2 and T3 $(\mathrm{P}>0.05)$. At $\mathrm{T} 1$ and $\mathrm{T} 2$, the HR of the control group was significantly higher than that of the LD, MD and HD groups $(\mathrm{P}<0.05)$. There was no significant difference in $\mathrm{HR}$ among the four groups at $\mathrm{T} 0$ and T3 $(\mathrm{P}>0.05)$. There was no significant difference in HR between the LD, MD and HD groups, or between different time-points within the group ( $\mathrm{P}>0.05)$ (Tables II and III).

Changes in MMSE scores of patients in the four groups before and after surgery. There were no significant differences in MMSE scores among the four groups 1 day before surgery, 3 days and 7 days after surgery $(P>0.05)$. The MMSE of the four groups decreased at 1 day after surgery $(\mathrm{P}<0.05)$. The MMSE scores of the control group were significantly lower than those of the LD, MD and HD groups at 1 day after surgery $(\mathrm{P}<0.05)$. There was no significant difference in MMSE scores among the LD, MD and HD groups at 1 day after operation $(\mathrm{P}>0.05)$ (Table IV).

Comparison of sedation scores of patients in the four groups at 6 and $12 \mathrm{~h}$ after operation. There were no significant differences in sedation scores among the four groups at 6 and $12 \mathrm{~h}$ after surgery $(\mathrm{P}>0.05)$, but the sedation scores at $6 \mathrm{~h}$ after surgery were higher than those at $12 \mathrm{~h}$ after surgery $(\mathrm{P}<0.05)($ Table V).

\section{Discussion}

Lung cancer threatens people's life, and the treatment is usually surgical resection (17). At present, the commonly used anesthesia method in the radical resection of lung cancer is general anesthesia combined with epidural anesthesia. The use of epidural anesthesia has an inhibitory effect on stress response, 
Table III. HR changes in the four groups of patients at different time-points.

\begin{tabular}{|c|c|c|c|c|c|c|}
\hline Time & LD group $(n=34)$ & MD group $(n=36)$ & HD group $(n=31)$ & Control group $(n=35)$ & F value & P-value \\
\hline T0 & $110.4 \pm 4.3$ & $111.1 \pm 4.2$ & $110.1 \pm 3.9$ & $111.8 \pm 3.6$ & 1.202 & 0.312 \\
\hline $\mathrm{T} 1$ & $112.7 \pm 3.9^{\mathrm{a}}$ & $110.1 \pm 4.1^{\mathrm{a}}$ & $111.4 \pm 4.1^{\mathrm{a}}$ & $124.7 \pm 5.1$ & 84.02 & $<0.001$ \\
\hline $\mathrm{T} 2$ & $111.2 \pm 4.1^{\mathrm{a}}$ & $109.9 \pm 3.9^{\mathrm{a}}$ & $110.2 \pm 4.3^{\mathrm{a}}$ & $115.6 \pm 6.1$ & 11.00 & $<0.001$ \\
\hline $\mathrm{T} 3$ & $110.5 \pm 4.4$ & $110.2 \pm 4.3$ & $109.9 \pm 3.9$ & $111.3 \pm 4.7$ & 0.649 & 0.585 \\
\hline $\mathrm{F}$ value & 2.193 & 0.597 & 0.868 & -54.84 & - & - \\
\hline P-value & 0.092 & 0.618 & 0.460 & $<0.001$ & - & - \\
\hline
\end{tabular}

${ }^{\mathrm{a}} \mathrm{P}<0.05$, compared with the control group at the same time-points. Repeated measures ANOVA was used for comparison at different time-points, and one-way ANOVA was used for comparison between the groups. The Bonferroni test was the post hoc test.

Table IV. Changes in MMSE scores before and after surgery in the four groups of patients.

\begin{tabular}{|c|c|c|c|c|c|c|}
\hline Time & $\begin{array}{l}\text { LD group } \\
(\mathrm{n}=34)\end{array}$ & $\begin{array}{l}\text { MD group } \\
\quad(n=36)\end{array}$ & $\begin{array}{l}\text { HD group } \\
(n=31)\end{array}$ & $\begin{array}{l}\text { Control group } \\
\qquad(\mathrm{n}=35)\end{array}$ & F value & P-value \\
\hline 1 day before surgery & $28.3 \pm 1.2$ & $29.1 \pm 0.8$ & $28.5 \pm 1.1$ & $28.8 \pm 0.9$ & 2.087 & 0.105 \\
\hline 1 day after surgery & $26.3 \pm 0.9^{\mathrm{a}, \mathrm{b}}$ & $26.7 \pm 0.5^{\mathrm{a}, \mathrm{b}}$ & $26.5 \pm 0.7^{\mathrm{a}, \mathrm{b}}$ & $20.3 \pm 0.4^{\mathrm{a}}$ & 793.6 & $<0.001$ \\
\hline 3 days after surgery & $28.1 \pm 0.7$ & $27.9 \pm 0.6$ & $27.8 \pm 0.9$ & $27.8 \pm 0.6$ & 1.361 & 0.258 \\
\hline 7 days after surgery & $28.1 \pm 0.6$ & $28.1 \pm 0.7$ & $27.9 \pm 0.7$ & $27.8 \pm 0.5$ & 1.971 & 0.122 \\
\hline $\mathrm{F}$ value & 49.57 & 81.31 & 30.97 & 1280 & - & - \\
\hline P-value & $<0.001$ & $<0.001$ & $<0.001$ & $<0.001$ & - & - \\
\hline
\end{tabular}

${ }^{a} \mathrm{P}<0.05$, compared with 1 day before surgery within the same group. ${ }^{\mathrm{b}} \mathrm{P}<0.05$, compared with the control group at 1 day after surgery. One-way analysis of variance was used in this table, and the Bonferroni test was the post hoc test.

Table V. Comparison of sedation scores among the four groups of patients at 6 and $12 \mathrm{~h}$ after operation.

\begin{tabular}{|c|c|c|c|c|c|c|}
\hline Time & $\begin{array}{l}\text { LD group } \\
\quad(n=34)\end{array}$ & $\begin{array}{l}\text { MD group } \\
\quad(n=36)\end{array}$ & $\begin{array}{l}\text { HD group } \\
\quad(n=31)\end{array}$ & $\begin{array}{l}\text { Control group } \\
\qquad(\mathrm{n}=35)\end{array}$ & $F$ value & P-value \\
\hline $6 \mathrm{~h}$ after surgery & $3.4 \pm 0.4$ & $3.5 \pm 0.5$ & $3.5 \pm 0.3$ & $3.6 \pm 0.7$ & 0.909 & 0.439 \\
\hline $12 \mathrm{~h}$ after surgery & $3.1 \pm 0.4$ & $3.1 \pm 0.6$ & $3.2 \pm 0.2$ & $3.2 \pm 0.6$ & 1.349 & 0.262 \\
\hline t value & 3.092 & 3.073 & 4.633 & 2.500 & - & - \\
\hline P-value & 0.003 & 0.003 & $<0.001$ & 0.015 & - & - \\
\hline
\end{tabular}

Univariate analysis of variance was used to compare scores among multiple groups and the scores between $6 \mathrm{~h}$ and $12 \mathrm{~h}$ after surgery, and the Bonferroni test was the post hoc test.

thereby maintaining hemodynamic stability, and epidural anesthesia can also reduce the use of anesthetic drugs and shorten patient's recovery time by inhibiting pain conduction $(18,19)$. Cisatracurium besilate is a non-depolarizing muscle relaxant drug, and N-methyltetrahydropapaverine is a metabolite of the drug. In the comparison with other muscle relaxants such as atracurium, it was found that $\mathrm{N}$-methyltetrahydropapaverine produced by the metabolism of atracurium is 10 times that of cisatracurium besilate, so symptoms of the central nervous system caused by $\mathrm{N}$-methyltetrahydropapaverine accumulation can be avoided by using cisatracurium besilate; cisatracurium besilate has the advantages of rapid onset, high efficacy and rapid recovery, and its clinical application value has been recognized $(20,21)$. However, there are still some controversies in the effect onset time and the effect on postoperative recovery of different doses of cisatracurium besilate (22). Therefore, this study explored the effect of different doses of cisatracurium besilate on hemodynamics and postoperative cognitive function recovery in patients undergoing radical resection of lung cancer, in order to provide a better solution for the clinical use of cisatracurium besilate.

To investigate whether the use of cisatracurium besilate makes a difference in blood pressure and HR, this study compared the mean arterial pressure and HR of patients with different doses of cisatracurium besilate during surgery. The results showed that there was no significant difference in 
mean arterial pressure and $\mathrm{HR}$ at $\mathrm{T} 0$ among the four groups $(\mathrm{P}>0.05)$. At $\mathrm{T} 1$, the mean arterial pressures of LD, MD and HD groups were significantly lower than that of the control group $(\mathrm{P}<0.05)$. There was no significant difference in the mean arterial pressure among the four groups at T2 and T3 $(\mathrm{P}>0.05)$. There was no significant difference in mean arterial pressure among the LD, MD and HD group at T0-T3 $(\mathrm{P}>0.05)$. However, the mean arterial pressure at $\mathrm{T} 1$ of the control group was higher than that at T0, T2 and T3 $(\mathrm{P}<0.05)$, and there was no significant difference in mean arterial pressure in the control group at $\mathrm{T} 2$ and $\mathrm{T} 3(\mathrm{P}>0.05)$. In addition, at T1 and T2, the HR of the control group was significantly higher than that of the LD, MD and HD groups $(\mathrm{P}<0.05)$. There was no significant difference in HR among the four groups at T3 $(\mathrm{P}>0.05)$. There was no significant difference in HR between the LD, MD and HD groups, or between different time-points within the group $(P>0.05)$, which indicated that the mean arterial pressure in patients administered with cisatracurium besilate was more stable than patients without atracurium, but the different dose of cisatracurium besilate had no significant effect on the mean arterial pressure during surgery. A previous study (23) on the efficacy of atracurium in neurosurgical anesthesia showed that patients with atracurium have a more stable mean arterial pressure, which is consistent with our conclusions. Also the effects of three doses of $0.15,0.2,0.3 \mathrm{mg} / \mathrm{kg}$ of cisatracurium besilate on intraoperative hemodynamics were previously studied (24), and the hemodynamics of different doses of cisatracurium besilate were all stable, which was consistent with our results.

According to the level of patients' education, MMSE score and Ramsay sedation score were used to evaluate the postoperative cognitive function recovery and agitation. The results showed that there was no significant difference in MMSE among the four groups 1 day before operation, 3 days after operation and 7 days after operation $(\mathrm{P}>0.05)$. The MMSE of the four groups decreased at 1 day after operation $(\mathrm{P}<0.05)$, and the MMSE score of the control group was significantly lower than that of the LD, MD and HD groups $(\mathrm{P}<0.05)$, indicating that the use of cisatracurium besilate can alleviate cognitive impairment at 1 day after surgery, but there was no significant difference in the recovery of postoperative cognitive function between different doses of cisatracurium besilate; the evaluation of patient agitation found that there were no significant differences in sedation scores among the four groups at 6 and $12 \mathrm{~h}$ after surgery $(\mathrm{P}>0.05)$, but the sedation scores at $6 \mathrm{~h}$ after surgery were higher than the sedation scores at $12 \mathrm{~h}$ after surgery $(\mathrm{P}<0.05)$, indicating that the use of cisatracurium besilate had no significant effect on patient's agitation. A study (25) has shown that the administration of cisatracurium besilate in special patients such as elderly, pediatrics and cardiovascular patients only causes slight changes in the onset time of muscle relaxation, and there was no significant effect on other aspects. In the research of Yu et al (26), the elimination rate of cisatracurium besilate was non-organ dependent and not significantly related to the dose, and the difference in pharmacokinetics in different patients was small, which also confirms our conclusions.

In summary, cisatracurium besilate can stabilize hemodynamics during radical resection of lung cancer, and can maintain stable HR and mean arterial pressure, and reduce the incidence of postoperative cognitive dysfunction. The effect is not significantly related with the dose, and cisatracurium besilate can be the first choice of muscle relaxant clinically.

\section{Acknowledgements}

Not applicable.

\section{Funding}

No funding was received.

\section{Availability of data and materials}

The datasets used and/or analyzed during the current study are available from the corresponding author on reasonable request.

\section{Authors' contributions}

QC drafted the manuscript. QC and YC were responsible for anesthesia. XT and CD analyzed the general data of patients. $\mathrm{HB}$ and $\mathrm{YC}$ helped with observation indicators. All the authors read and approved the final manuscript.

\section{Ethics approval and consent to participate}

This study was approved by the Ethics Committee of Dongying People's Hospital (Dongying, China). Patients who participated in this study had complete clinical data. Signed informed consents were obtained from the patients or the guardians.

\section{Patient consent for publication}

Not applicable.

\section{Competing interests}

The authors declare that they have no competing interests.

\section{References}

1. Reck M, Rodríguez-Abreu D, Robinson AG, Hui R, Csőszi T, Fülöp A, Gottfried M, Peled N, Tafreshi A, Cuffe S, et al; KEYNOTE-024 Investigators: Pembrolizumab versus chemotherapy for PD-L1-positive non-small-cell lung cancer. N Engl J Med 375: 1823-1833, 2016.

2. Zhang Y, Sui J, Shen X, Li C, Yao W, Hong W, Peng H, Pu Y, Yin L and Liang G: Differential expression profiles of microRNAs as potential biomarkers for the early diagnosis of lung cancer. Oncol Rep 37: 3543-3553, 2017.

3. Deng Y, Hao Z and Fu X: Development, application details, and prospects of Uni-VATS on lung cancer radical operation under the concept of 'precise medical treatment'. Zhongguo Fei Ai Za Zhi 19: 371-376, 2016 (In Chinese).

4. Zheng Y and Bueno R: Commercially available prognostic molecular models in early-stage lung cancer: A review of the Pervenio Lung RS and Myriad myPlan Lung Cancer tests. Expert Rev Mol Diagn 15: 589-596, 2015.

5. Shen L, Luo Y, Lu Z, Hu X, Ding W and Yu B: Cost-effectiveness of different regimens of anesthesia for day surgery in China. Int J Clin Exp Med 7: 5744-5750, 2014.

6. Jia ZM, Hao HN, Huang ML, Ma DF, Jia XL and Ma B: Influence of dexmedetomidine to cognitive function during recovery period for children with general anesthesia. Eur Rev Med Pharmacol Sci 21: 1106-1111, 2017 
7. Tufail M, Hussain M, Russell R, Nasimudeen A, Martin N and Panchal R: Success rate of local anaesthetic video assisted thoracoscopy (LAVAT) talc poudrage for malignant pleural effusions at a UK tertiary centre. Lung Cancer 87 (Suppl 1): S20, 2015.

8. Gunatilake S, Parker L, Bishop L, Babu S, Clark R and Chauhan A: Operator sensitivity for pleural malignancy at medical thoracoscopy. Lung Cancer 87 (Suppl 1): S18-S19, 2015.

9. Rahimzadeh P, Faiz SHR, Alebouyeh MR, Dasian A and Sayarifard A: Appropriate anesthesia regimen to control sevoflurane-induced emergence agitation in children; propofollidocaine and thiopental sodium-lidocaine: A randomized controlled trial. Iran Red Crescent Med J 16: e16388, 2014.

10. Movafegh A, Amini S, Sharifnia H, Torkamandi H, Hayatshahi A and Javadi M: Cost analysis and safety comparison of cisatracurium and atracurium in patients undergoing general anesthesia. Eur Rev Med Pharmacol Sci 17: 447-450, 2013.

11. Grosse-Sundrup M, Henneman JP, Sandberg WS, Bateman BT, Uribe JV, Nguyen NT, Ehrenfeld JM, Martinez EA, Kurth T and Eikermann M: Intermediate acting non-depolarizing neuromuscular blocking agents and risk of postoperative respiratory complications: Prospective propensity score matched cohort study. BMJ 345: e6329, 2012.

12. Cope TM and Hunter JM: Selecting neuromuscular-blocking drugs for elderly patients. Drugs Aging 20: 125-140, 2003.

13. Ghodraty MR, Saif AA, Kholdebarin AR, Rokhtabnak F, Pournajafian AR, Nikzad-Jamnani AR, Shah A and Nader ND: The effects of magnesium sulfate on neuromuscular blockade by cisatracurium during induction of anesthesia. J Anesth 26 : 858-863, 2012.

14. Sharrock NE: Epidural anesthetic dose responses in patients 20 to 80 years old. Anesthesiology 49: 425-428, 1978.

15. Yang XH, Bai Q, Lv MM, Fu HG, Dong TL and Zhou Z: Effect of dexmedetomidine on immune function of patients undergoing radical mastectomy: A double blind and placebo control study. Eur Rev Med Pharmacol Sci 21: 1112-1116, 2017.

16. Ramsay MA, Savege TM, Simpson BR and Goodwin R: Controlled sedation with alphaxalone-alphadolone. BMJ 2: 656-659, 1974

17. Zappa $C$ and Mousa SA: Non-small cell lung cancer: Current treatment and future advances. Transl Lung Cancer Res 5 : 288-300, 2016.
18. Esteve N, Ferrer A, Sansaloni C, Mariscal M, Torres M and Mora C: Epidural anesthesia and analgesia in liver resection: Safety and effectiveness. Rev Esp Anestesiol Reanim 64: 86-94, 2017 (In Spanish).

19. Soni P: Comparative study for better adjuvant with ropivacaine in epidural anesthesia. Anesth Essays Res 10: 218-222, 2016.

20. Mroziński P,Lango R, Biedrzycka A, Kowalik MM,Pawlaczyk R and Rogowski J: Comparison of haemodynamics and myocardial injury markers under desflurane vs. propofol anaesthesia for off-pump coronary surgery. A prospective randomised trial. Anaesthesiol Intensive Ther 46: 4-13, 2014.

21. Gharedaghi MH, Rahimian R, Dehpour AR, Yousefzadeh-Fard Y and Mohammadi-Farani A: Dinitrobenzene sulphonic acidinduced colitis impairs spatial recognition memory in mice: Roles of N-methyl D-aspartate receptors and nitric oxide. Psychopharmacology (Berl) 232: 3081-3090, 2015.

22. Yu DJ and Gao HY: Influences of cisatracurium besylate and vecuronium bromide on muscle relaxant effects and electromyography of tracheal intubation under general anesthesia. Eur Rev Med Pharmacol Sci 21: 1974-1979, 2017.

23. Minton MD, Stirt JA, Bedford RF and Haworth C: Intracranial pressure after atracurium in neurosurgical patients. Anesth Analg 64: 1113-1116, 1985.

24. Voss J, Riedel T, Sommer M and Rosolski T: Cis-atracurium - an equivalent substitution for atracurium in pediatric anesthesia? Anaesthesiol Reanim 27: 93-97, 2002 (In German).

25. Sator-Katzenschlager SM, Oehmke MJ, Kontaratos M, Wedrich A, Heinze G and Weinstabl C: Effect of different doses of cisatracurium on intraocular pressure in sedated patients. Eur J Anaesthesiol 19: 823-828, 2002.

26. Yu H, Yang XY and Liu B: EMLA Cream coated on the rigid bronchoscope for tracheobronchial foreign body removal in children. Laryngoscope 119: 158-161, 2009.

This work is licensed under a Creative Commons Attribution-NonCommercial-NoDerivatives 4.0 International (CC BY-NC-ND 4.0) License. 